Chapter 11

\title{
Hepatitis C Infection in Kidney Transplantion
}

\author{
A.A. Amir, R.A. Amir and S.S. Sheikh \\ Additional information is available at the end of the chapter \\ http://dx.doi.org/10.5772/55648
}

\section{Introduction}

Hepatitis $\mathrm{C}$ is one of the commonest chronic viral infections world-wide and has major healthcare implications. According to World Health Organization (WHO), the estimated prevalence of chronic $\mathrm{HCV}$ infection world-wide ranges from $0.1 \%$ to more than $12 \%$, equating to approximately 170 million chronic carriers and incidence of 3-4 million new cases per year (Carbone et al., 2011). Chronic kidney disease (CKD) in general is present in approximately $10 \%$ of the population withmany of these patients requiring renal replacement therapyintheform of dialysis and orkidney transplant. A major cause of morbidity and mortality indialysis patientsand kidney transplant recipients is liver disease secondary to hepatitis $\mathrm{C}$ virus (HCV) infection. The prevalence of $\mathrm{HCV}$ infection is high among renal transplant donors, recipients, and in end stage renal disease(ESRD) patients on dialysis. When HCV infection is present in this group of patients, it has major implications (Scott et al., 2010; Goodkin et al., 2003; Carbone et al., 2011). The major factorsassociated with thisincreased relativerisk of HCV infectionin dialysis patients as opposed togeneral populationareoverallexposureofblood products, age, and durationofdialysis(Periera \& Levey, 1997; Finelli et al., 2005; Fissell et al., 2004). On the other hand, some recent reports indicate possible decline in prevalence of HCV infection in dialysis patients (Carbone et al., 2011; Scott et al., 2010; Finelli et al., 2005; Fissell et al., 2004; Jadoul et al., 2004; Fribrizi et al., 2002). This decline could be related to the use of erythropoiesis-stimulating agents that consequently lead to decrease in blood transfusions, and progressive enhancement of dialysis conditions to control infections. In developed countries, the prevalence of HCV infection is higher in renal transplant recipients than in dialysis patients, major contributing factors being longer survival of the former with more exposure to blood products, and most probably dialysis.

\section{Natural history of HCV infection, morbidity and mortality in transplant}

HCV RNA can be detected in the blood after 1-3 weeks of first exposure. In majority of the HCV acute infection cases the patients are asymptomatic, however the disease can have a fulminant 
course. The natural history of Hepatitis $C$ infection is quite variable with disease spectrum varying from mild to severe hepatitis, hepatic cirrhosis, and hepatocellular carcinoma. In 60-85\% of these cases, HCV RNA can be detected for 6 months or longer. $10-15 \%$ of these chronic patients progress to develop liver cirrhosis (National Institute of Health [NIH], 2002). The virus is very slow to progress with almost no signs or symptoms in the first few years or decade. The most reliable tool to examine the progression of HCV liver damage is histologic evaluation of liver biopsy. The activity of liver disease can fluctuate, however, once there is fibrosis the damage is considered to be irreversible and progressive. Poynard, in 2001, reported that the average time of HCV infection to progress to liver cirrhosis is about 30 years, ranging from 13 years (for men who drank and were infected after the age of 40 years) to 42 years (for women who did not drink and were infected before the age of 40) (Poynard et al., 2001).

$\mathrm{HCV}$ infection has been associated independently with increased mortality in Hemodialysis patients as shown by several studies including Dialysis Outcomes and Practice Patterns (DOPPS) conducted over three continents (Goodkin et al., 2003; Fibrizi, 2004, 2007).

Transplant recipients from HCV positive donors have a higher rate of fulminant or severe hepatitis and liver disease in general. The literature shows some controversy in results presented by various studies regarding survival. The overall survival and specifically of the allograft survival for HCV infected kidney transplant recipients are much worse than noninfected renal transplant recipients (Figures 1 \& 2) (Pedroso et al., 2006). Several studies have shown that although recipients of organs from HCV infected donors have higher rates of liver disease, there is no solid evidence of decreased overall survival rate (Periera, 1991, 1995; Mendez et al., 1995). On the other hand, there are some other studies that show contrary results with recipients of organs from HCV infected donors to have significantly higher morbidity mainly due to liver disease and reduced overall survival with limited life expectancy (Pirsch et al., 1995). The presence of liver damage depending on the severity as determined by biopsy is a strong predictor of liver failure and death post-transplantation. Despite the ongoing controversy, majority of the data shows increased morbidity due to higher rate of liver disease. However, there is no consensus on lack of adverse effect on survival by initial studies that mostly represented comparatively small number of cases and short period of followup. Fabrizi and colleagues pooled these single studies in a meta-analysis and showed that anti HCV positive status is an independent and significant risk factor for death and graft failure after kidney transplantation with estimated relative risk of 1.79 and 1.56 respectively. In a recent study, Scott and colleagues also showed prevalence of HCV infection in renal transplant recipients to be $1.8 \%$ and reported the patient survival to be $77 \%$ and $90 \%$ at 5 years and $50 \%$ and $79 \%$ at 10 years for HCV antibody positive and HCV antibody negative groups. The most common causes of death in HCV positive kidney transplant recipients were cardiovascular disease, malignancy, and liver failure (Scott et al., 2010). In addition to increased mortality, Zylberberg et al found a significantly increased yearly progression rate of liver inflammation and fibrosis in $\mathrm{HCV}$ infected renal transplant recipients than immunocompetent group (Zylberberg et al., 2002). Alric and colleagues, on the contrary, showed the annual progression of liver fibrosis to be significantly lower in renal transplant recipients than patients with HCV and normal renal function (Alric et al., 2002). Reasons for the above mentioned difference is not clear. There is strong evidence that transplantation with kidney from HCV infected donor 
is significantly associated with improved survival as opposed to remaining on dialysis on transplant wait list (Abbott et al., 2004; Periera et al., 1998; Knoll et al., 1997; Maluf et al., 2007). Findings suggest that detrimental effect of transplantation in association with HCV infection does not outweigh its long term benefits on survival in end stage renal disease (ESRD) patients on dialysis and therefore anti-HCV positivity should not be considered as an absolute contraindication for renal transplantation (Natov \& Periera, 2012; Knoll et al, 1997).

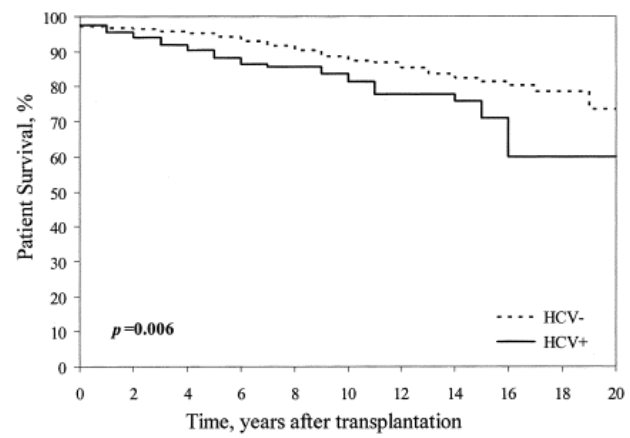

Figure 1. Kaplan-Meier estimate of the cumulative probability of patient survival. Reprinted from Transplantation Proceedings, 38, 1890-1894 (2006), Pedroso S et al., Impact of Hepatitis C Virus on Renal Transplantation: Association with Poor Survival. With permission from Elsevier through Copyright Clearance Center

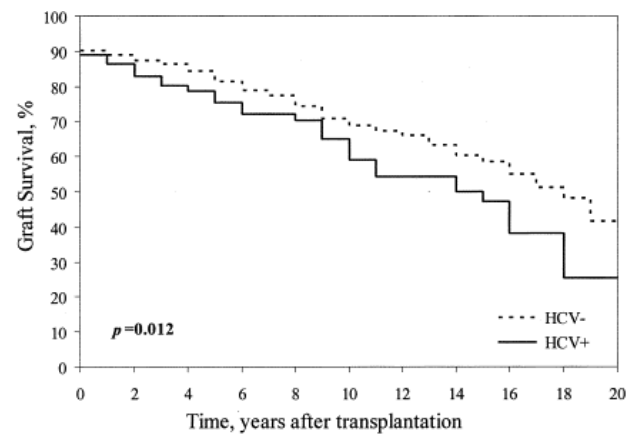

Figure 2. Kaplan-Meier estimate of the cumulative probability of graft survival.Reprinted from Transplantation Proceedings, 38, 1890-1894 (2006), Pedroso S et al., Impact of Hepatitis C Virus on Renal Transplantation: Association with Poor Survival. With permission from Elsevier through Copyright Clearance Center

The increased morbidity and mortality in HCV infection is not only related to liver disease but also extrahepatic complications (Kidney disease: improving global outcome [KDIGO], 2008). $\mathrm{HCV}$ infection can predispose to the development of pre and posttransplant diabetes. A 2005 meta-analysis of 2502 patients noted a fourfold increase in the development of New Onset Diabetes mellitus after Transplantation (NODAT) among HCV infected patients when compared to the non-infected group (Gursoy et al., 2000; Abbott et al., 2004). It is suggested 
that $\mathrm{HCV}$ infection might be associated with increased insulin resistance contributing to development of NODAT.

HCV has been associated with renal disease in both native and transplanted kidneys. It is in fact reported to be more associated with glomerular disease in renal transplants than native kidneys. This association is suggested to be secondary to immunosuppressive therapy leading to increased HCV RNA titres (Periera et al., 1995; Burstein \& Rodby, 1993). In renal transplant recipients, $\mathrm{HCV}$ infection has been implicated in pathogenesis of acute glomerulopathy, de novo immune complex glomerulonephritis in allograft, and chronic allograft nephropathy (CAN) (Cosio et al., 1996; Roth et al., 1995; Ozdemir et al., 2006; Morales et al., 1997; Mahmoud et al., 2005). De novo membranoproliferative glomerulonephritis (MPGN), and de novo membranous glomerulonephritis (MGN), with or without mixed cryoglobulinemia are the most frequent glomerular patterns of injury seen in association with $\mathrm{HCV}$ infection in renal allografts. In 2001, one study reported the prevalence of de novo MPGN and MGN to be $45.4 \%$ and $18.2 \%$ in $\mathrm{HCV}$ positive transplant recipients as compared to $5.7 \%$ and $7.7 \%$ in $\mathrm{HCV}$ negative recipients (Cruzado et al., 2001). Subsequently, another study in 2006 reported the prevalence of de novo GN to be $34 \%$ in $\mathrm{HCV}$ infected recipients and only $6.6 \%$ in HCV negative recipients (Ozdemir et al., 2005). In general higher prevalence of autoimmune GN was associated with poor graft outcome, and even worse than de novo GN in HCV negative patients (Carbone et al., 2011).

Proteinuria is a common manifestation of kidney disease in HCV infected patients and renal biopsy is used to establish the diagnosis of glomerular injury, however currently it is impossible to determine $\mathrm{HCV}$ as the cause of glomerular damage based solely on morphologic assessment of renal biopsy. (Natov \& Periera, 2012).

In 2005, Mahmoud et al reported a higher rate of CAN in HCV infected patients who did not receive interferon (IFN) therapy prior to renal transplant. Recent data also shows increased rate of graft failure due to $\mathrm{CAN}$ in $\mathrm{HCV}$ positive recipients than HCV negative (Scott et al., 2010). The Spanish Chronic Allograft Nephropathy Group analyzed 4304 renal transplant recipients with 587 of them being HCV positive over a period of 1990 to 2002. The study reported $\mathrm{HCV}$ infection to be associated with early proteinuria, lower renal function, de novo GN, chronic rejection, graft loss, and lower survival than HCV negative recipients (Morales et al., 2010). Another implication of HCV infection is its association with development of early graft dysfunction due to acute glomerular lesion. Examples of such lesions include acute transplant glomerulopathy, and de novo renal thrombotic microangiopathy (Cosio et al., 1996, Baid et al., 1995). Acute transplant glomerulopathy is mostly considered to be an atypical variant of acute cellular rejection and is also present more commonly in HCV positive recipients (Cosio et al., 1996a, 1996b).

\section{Diagnosis}

Detection of HCV infection is based primarily on the type of laboratory test used and its sensitivity and specificity. Any false positive tests will lead to unnecessary waste of precious 
potential organs for transplant (Natov \& Periera, 2012). A large collaborative study was performed in United States that looked at the positive and negative predictive values of antibody screening tests. Eight organ procurement organizations representing different geographical regions studied 3078 cadaver organ donors. Using first generation enzyme linked immunosorbent assay ELISA1 anti-HCV test, the prevalence was found to be $5.1 \%$ (1.5-16.7\%). Using the second generation ELISA2, the prevalence was $4.2 \%$, with positive predictive value of $55 \%$ and negative predictive value of $100 \%$. Some investigators have suggested the use of third generation ELISA3 tests to screen cadavers for HCV that because of its improved specificity showed only $3.7 \%$ prevalence. On the other hand, the prevalence of HCV RNA (ribonuclease acid) detection by Polymerase chain reaction (PCR) was only $2.4 \%$. Although discarding all ELISA2 positive organs would eliminate transmission of $\mathrm{HCV}$, there will be waste of $1.8 \%$ that will be discarded based on ELISA2 positivity while they are HCV RNA negative. However, it is currently not practical to test cadavers for HCV RNA status prior to organ procurement (Challine et al., 2004). The current practice in major centers is still to screen organ donors for antibodies against HCV. The serum aminotransferase levels are usually normal in uremic patients, and therefore are not considered reliable in determining disease activity and severity of fibrosis in this group. For clinically suspicious patients with elevated serum aminotransferase levels but negative antibody test, an HCV RNA assay with a detection limit of less than $50 \mathrm{IU} / \mathrm{mL}$ is recommended to rule out infection (Pawlotsky, 2002).

There is limited data on the impact of different HCV genotypes on survival after transplantation. Data reported by New England Organ Bank had relatively small number of patients and HCV genotype distribution to reach a conclusion (Natov et al., 1999).

Liver biopsy remains the gold standard for assessment of liver damage and fibrosis. Several scoring systems are used for assessment of hepatic fibrosis that use various criteria such as activity index and special stains for collagen deposition. Examples of these scoring systems include hepatic activity index (HAI), Knodell score and the Matavir system. Patients with HCV infection can have evidence of histologic liver disease in the absence of elevated transaminases and abnormal liver function tests. Therefore there may be merit in performing liver biopsy on all anti-HCV positive patients on transplant wait list. In patients with histologic evidence of liver disease, the decision to proceed or not with transplantation should be made with extreme caution as post-transplant immunosuppression may exacerbate liver disease (Zylerberg et al., 2002).

\section{Clinical outcome with impact of HCV status before transplantation, and use of allografts from $\mathrm{HCV}$ positive donors}

HCV has multiple distinct variants that are classified into six major types based on the viral genome sequence analysis. Each type consists of subtypes named in order of discovery such as $a, b, c$ and so on, the subtypes may include individual isolates. Repeated infection or superinfection may occur in the same patient by the same or a different strain as HCV does 
not provide immunity. Thus transplant recipients that are positive for HCV RNA may have the viral genotype of the donor, same genotype as present pretransplant or both individual genotypes. The impact of superinfection is not clear, however there is some evidence that HCV infection by one or multiple strains does not impact the survival negatively, at least in the short term (Natov et al., 1999; Natov \& Periera, 2012; Ali et al., 1998).

The use of renal allografts from HCV positive donors to be transplanted in HCV infected recipients may offer some advantage (Figure 3) (Abbott et al., 2003). This approach is consistent with 2008 Kidney Disease: Improving Global Outcomes (KDIGO) Guideline recommendations (KDIGO, 2008). A survey was performed in United States on 245 transplant centers with response obtained from 147 centers. The data showed that $49 \%$ of these centers use HCV seropositive donors (Batiuk et al., 2002). Patients who are HCV positive before transplant have a significantly higher risk of developing posttransplant liver disease, mainly chronic hepatitis and its sequelae. An unusual serious form of liver involvement termed fibrosing cholestatic hepatitis has been reported in such patients. it is characterized by severe cholestasis, extensive fibrosis, and rapidly progressive liver failure, and is most likely related to acute infection under maximum immunosuppression (Toth et al., 1998; Delladetsima et al., 2006). Kidney transplant in $\mathrm{HCV}$ positive patients is associated with a 1.8-30.3 fold increase in serum viral titer most likely due to increased viral proliferation secondary to immunosuppressive therapy. However, this increase in viral titer may not be associated with increased risk of posttransplant liver disease, neither does it have any association with transaminase pattern or histologic severity of liver injury (Natov \& Periera, 2012; Periera et al., 1995; Rpth et al., 1996).

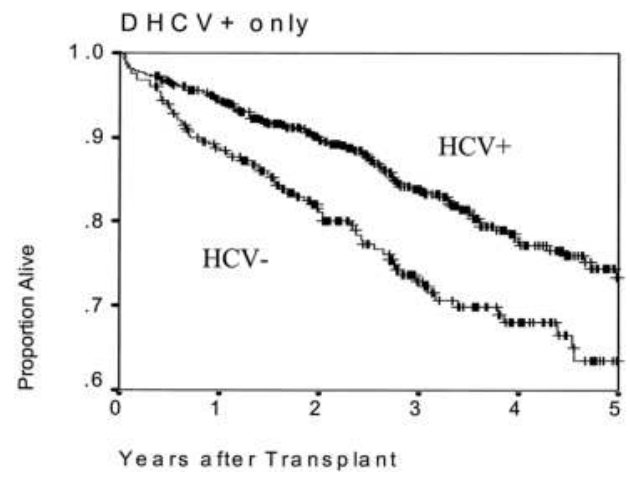

Figure 3. Kaplan-Meier plot of patient survival after renal transplantation, limited to patients who received a kidney positive for hepatitis $\mathrm{C}(\mathrm{DHCV}+; n=873)$ stratified by recipients who were HCV+ and HCV-. Reprinted from J Am Soc Nephol, 14, 2908-2918 (2003), Abbott K et al., Hepatitis C and Renal Transplantation in the Era of Modern Immunosuppression. With permission through Copyright Clearance Center

Mycophenolate mofetil and antithymocyte globulin are reported to increase HCV viremia while cyclosporine was found to have a suppressive effect on HCV replicon RNA level and HCV protein expression in cultured human hepatocytes (Figure 4) (Abbott et al., 2003; Rostaing et al., 2000; Geith, 2011; Misiani et al., 1994). 


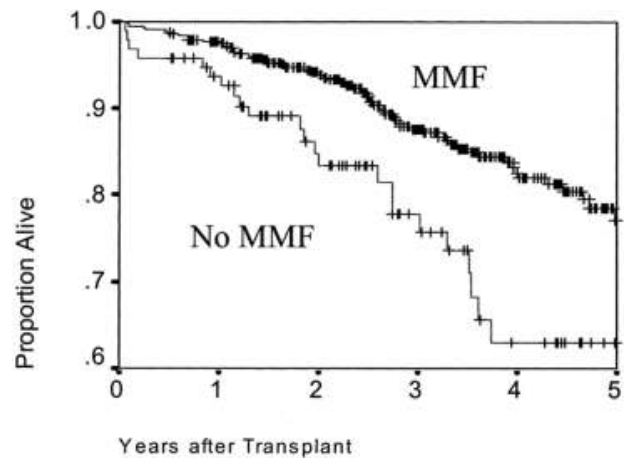

Figure 4. Kaplan-Meier plot of patient survival after renal transplantation, limited to patients who received a kidney positive for hepatitis $\mathrm{C}(\mathrm{DHCV}+; \mathrm{n}=873)$ stratified by recipients who received mycophenolate mofetil (MMF) or those who did not (no MMF). Reprinted from J Am Soc Nephol, 14, 2908-2918 (2003), Abbott K et al., Hepatitis C and Renal Transplantation in the Era of Modern Immunosuppression. With permission through Copyright Clearance Center

Although there is solid data that shows increased risk of developing liver disease in HCV positive patients, there are conflicting reports and data regarding impact on survival. Some studies failed to show any difference in overall survival in transplant recipients that were HCV positive or negative. Other studies of pretransplant $\mathrm{HCV}$ positive recipients reported increased mortality rate mainly due to liver disease and sepsis with a 3.3 fold increased risk of death and 9.9 fold higher risk of mortality due to sepsis (Natov \& Periera, 2012; Periera et al., 1995; Legendre et al., 1998). A 2005 meta-analysis on eight clinical trials involving a cohort of 6365 patients showed an increased relative risk of death in HCV positive patients (1.79) mainly due to liver cirrhosis and cancer. In addition the relative risk of allograft failure was 1.56 (Fabrizi et al., 2005).

Studies conducted in the 80 s and 90 s showed $35 \%$ of recipients who received allografts from $\mathrm{HCV}$ positive donors developed posttransplant liver disease, $50 \%$ became anti $\mathrm{HCV}$ positive after transplant, and 73\% developed HCV viremia (Natov, 2002; Periera et al., 1994). The wide variation in the rate of transmission could be related to different prevalence among donors, difference in organ preservation and failure to test recipients in some centers. A large registry analysis in 2002 showed increased mortality in recipients of allografts from HCV positive donors regardless of the HCV status of the recipient (Bucci et al., 2002). Using the data from the Organ Procurement and Transplantation Network (OPTN), Maluf reported approximately 300 days shortening of wait time for $\mathrm{HCV}$ positive recipients receiving allografts from $\mathrm{HCV}$ positive donors compared with $\mathrm{HCV}$ negative recipients however there was significantly decreased graft and patient overall survival (Maluf et al., 2010). A larger analysis of the same data from OPTN was performed recently by Northup and colleagues in 2010 that included $19496 \mathrm{HCV}$ positive recipients and $934 \mathrm{HCV}$ positive donors. It showed the adjusted hazard ratio for death to be similar for $\mathrm{HCV}$ positive recipients of $\mathrm{HCV}$ positive donors and $\mathrm{HCV}$ positive recipients of $\mathrm{HCV}$ negative donors. The worst survival was seen in $\mathrm{HCV}$ negative recipients who received allografts from HCV positive donors (Northup et al., 2010). 
In regards to superinfection, $\mathrm{HCV}$ genotype 1 is the most common genotype of HCV seen in Western countries and is notorious to be less responsive to antiviral therapy including Pegylated IFN and Ribavirin. Some authorities suggest that genotyping should be done routinely and genotype 1 renal allografts should not be used in recipients with other genotypes. However data is limited regarding this strategy (Carbone et al., 2011).

\section{Treatment}

In non-transplant setting, the combination therapy with interferon (IFN) and Ribavirin is the standard of care for treatment of initial as well as relapse of HCV infection. Clearance of Ribavirin is impaired in patients with renal dysfunction as the drug itself and its metabolites cannot be removed by Hemodialysis. Therefore, Ribavirin is not recommended in patients with creatinine clearance of less than $50 \mathrm{~mL} / \mathrm{min}$. IFN therapy is however recommended in dialysis patients. The goal of pretranslant $\mathrm{HCV}$ treatment is to attempt to eradicate HCV before transplant subsequently leading to decrease in the risk of progression of $\mathrm{HCV}$-associated liver disease, reduced risk of posttransplant renal dysfunction, and possible reduction in HCV disease progression. The optimal treatment of $\mathrm{HCV}$ in dialysis patients is regarded as IFN therapy but it is not known whether there is any added advantage on the use of pegylated IFN over nonpegylated standard IFN. Dialysis patients are not considered candidates of combination therapy owing to concerns regarding development of Ribavirin-induced anemia as the clearance of the drug is impaired in patients with renal dysfunction. A safer but less costeffective approach is to use IFN therapy to treat HCV positive patients on dialysis who are potential transplant candidates. This strategy seems to have a beneficial effect on the course of liver disease posttransplant, shows higher rates of sustained biochemical and virological response, and seems to have reduced risk of HCV disease progression. At present data on relapse rate on $\mathrm{HCV}$ positive patients treated pretransplant is limited and controversial. 2008 KDIGO guidelines suggest HCV positive transplant candidates to be considered for IFN therapy before transplant. Ribavirin is not recommended because of its impaired clearance. Similar concerns apply to pegylated IFN because of its longer half-life and is also not recommended for pretransplant HCV therapy.

Posttransplant HCV treatment is generally not recommended. A major limitation to the use of IFN posttransplant is the potential of developing acute rejection. In addition to antiviral activity, IFN also has pleiotropic effects including antiproliferative and immunomodulatory functions. The National Institute of Health (NIH) Consensus Statement on management of $\mathrm{HCV}$ infection lists renal transplant as one of the contraindications to IFN therapy. Most authorities are in line with this approach because of the increased risk of acute rejection, high cost, limited efficacy, and significant side effects that are reported with IFN treatment after transplant. Treatment may be recommended in exceptional and life-threatening cases of HCV complications such as fibrosing cholestatic hepatitis, life-threatening vasculitis, recurrent and progressive $\mathrm{HCV}$-associated glomerulopathy in the transplanted kidney, and advanced histologic stages of liver fibrosis. 
2008 KDIGO guidelines recommend monotherapy with standard IFN only to be considered in HCV positive kidney transplant recipients (Terraut \& Adey, 2007; Kim et al., 2011; Carbone et al., 2011; Natov \& Periera, 2012. Data on efficacy of Ribavirin treatment alone after transplant is limited. Combination therapy is the most likely regimen to achieve a sustained virologic response (SVR), however Ribavirin dosage must be adjusted based on the renal function to minimize the complication of anemia.

Large scale, multicenter clinical trials are needed to determine the optimal treatment approach in these populations. New therapies may offer specific advantages and show decreased incidence of treatment-related side effects than the currently available drugs.

In addition SVR to antiviral therapy in patients with HCV associated renal disease has been associated with improvement in renal histology with reduced inflammation and immune deposits. Recently, five HCV positive renal transplant patients who developed type III cryoglobulinemic MPGN were successfully treated by Rituximab (anti-CD 20) chimeric monoclonal antibody (Basse et al., 2005, 2006).

Transplantation after adequate antiviral therapy followed by minimal immunosuppression can be a good option. Recently, Shah and colleagues evaluated graft function and graft as well as patient survival in retrospective analyses of $132 \mathrm{HCV}$-positive renal transplant patients who received tolerance induction protocol (TIP) with minimal immunosuppression and compared them with 79 controls transplanted using standard triple immunosuppression drugs. TIP consisted of 1 donor-specific transfusion, peripheral blood stem cell infusion, portal infusion of bone marrow, and target-specific irradiation. In the TIP group patient survival at 1, 5, and 10 years was $92.4 \%, 70.4 \%$, and $63.7 \%$, respectively, versus $75.6 \%, 71.7 \%$, and $55.7 \%$ in the control group. The graft survival was $92.9 \%, 81.5 \%$, and $79.1 \%$ versus $91.7 \%, 75.7 \%$, and $67.7 \%$, respectively. Rejection episodes were less frequent in the former group. Abnormal liver enzymes were seen in $22 \%$ patients in the TIP group versus $31 \%$ of the control group (Shah et al., 2011).

\section{Conclusion}

$\mathrm{HCV}$ infection is relatively common among patients with ESRD on dialysis and kidney transplant recipients. It is a major cause of morbidity and mortality among this group. When indicated, treatment with IFN and antiviral therapy should be commenced prior to kidney transplantation. The optimal treatment of transplant patients with HCV infection is not known. IFN is not recommended posttransplant because of potential risk of rejection. However there are some life threatening HCV related complications that would compel the use of IFN in a renal transplant recipient. In conclusion, Ribavirin is contraindicated in dialysis patients and alternative drugs are needed to enhance antiviral effects of IFN. For renal transplant recipients, Ribavirin can be used in combination with IFN in patients with restored renal function, however the risk of acute rejection with IFN therapy remains a serious concern. Alternative drugs are also needed with better safety and efficacy for treatment of HCV posttransplant. Despite the ongoing dilemma HCV positive renal transplant recipients have a better survival 
than HCV positive patients awaiting transplantation. Data shows strong evidence that use of allografts from $\mathrm{HCV}$ positive donors leads to reduced wait time for $\mathrm{HCV}$ positive recipients however there is conflicting data about graft and overall survival that needs to be further studied. In addition transplant of kidneys from HCV positive donors should be restricted to recipients with $\mathrm{HCV}$ viremia at the time of transplant.

\section{Author details}

A.A. Amir ${ }^{1}$, R.A. Amir ${ }^{2}$ and S.S. Sheikh ${ }^{3}$

1 Consultant Nephrologist, Dhahran Health Center, Saudi Aramco Medical Services Organization, Dhahran, Saudi Arabia

2 Dammam University, Dhahran, Saudi Arabia

3 Chief, Pathology and Laboratory Services, Dhahran Health Center, Saudi Aramco Medical Services Organization, Dhahran, Saudi Arabia

\section{References}

[1] Abbott, K, Bucci, J, Matsumoto, C, et al. Hepatitis C and renal transplantation in the era of modern immunosuppression. Journal of American Society of Nephrology, (2003). doi:ASN.0000090743.43034.72, 14, 2908-2918.

[2] Abbott, K. C, Lentine, K. L, Bucci, J. R, et al. The impact of transplantation with deceased donor hepatitis c-positive kidneys on survival in wait-listed long-term dialysis patients. Am J Transplant (2004).

[3] Abbott, K, Lentine, K, Bucci, J, et al. Impact of diabetes and hepatitis after kidney transplantation on patients who are affected by hepatitis $\mathrm{C}$ virus," Journal of the American Society of Nephrology, (2004). , 15(12), 3166-3174.

[4] Ali, M. K, Light, J. A, Barhyte, D. Y, et al. Donor hepatitis C virus status does not adversely affect short-term outcomes in $\mathrm{HCV}+$ recipients in renal transplantation. Transplantation (1998).

[5] Alric, L. DiMartino V, Selves J, et al., "Long-term impact of renal transplantation on liver fibrosis during hepatitis C virus infection," Gastroenterology, (2002). , 123(5), 1494-1499.

[6] Baid, S, Pascual, M, Williams, W, et al. Renal thrombotic microangiopathy associated with anticardiolipin antibodies in hepatitis $C$ virus-infected renal allograft recipients," Transplantation, (1995). , 59, 1676. 
[7] Burstein, D. M, \& Rodby, R. A. Membranoproliferative glomerulonephritis associated with hepatitis C virus infection. J Am Soc Nephrol (1993).

[8] Basse, G, Ribes, D, Kamar, N, Mehrenberger, M, Esposito, L, Guitard, J, Lavayssière, L, Oksman, F, Durand, D, Dur, D, \& Rostaing, L. Rituximab therapy for de novo mixed cryoglobulinemia in renal transplant patients. Transplantation. (2005).

[9] Basse, G, Ribes, D, Kamar, N, Mehrenberger, M, Sallusto, F, Esposito, L, Guitard, J, Lavayssière, L, Oksman, F, Durand, D, \& Rostaing, L. Rituximab therapy for mixed cryoglobulinemia in seven renal transplant patients. Transplant Proc. (2006).

[10] Batiuk, T. D, Bodziak, K. A, \& Goldman, M. Infectious disease prophylaxis in renal transplant patients: a survey of US transplant centers. Clin Transplant (2002).

[11] Bucci, J, Matsumoto, C, Swanson, S, Agodoa, L, Holtzmuller, K, \& Abbott, K. Donor hepatitis $\mathrm{C}$ seropositivity: clinical correlates and effect on early graft and patient survival in adult cadaveric kidney transplantation," Journal of the American Society of Nephrology, (2002). , 13(12), 2974-2982.

[12] Carbone, M, Cockwell, P, \& Neuberger, J. Hepatitis c and kidney transplantation. International journal of nephrology, 2011(593291), 1-17. doi:

[13] "NIH consensus statement on management of hepatitis C: (2002). NIH Consens State Sci Statements, , 19(3), 1-46.

[14] Challine, D, Pellegrin, B, Bouvier-alias, M, et al. HIV and hepatitis C virus RNA in seronegative organ and tissue donors, Lancet (2004).

[15] Cosio, G, Sedmak, D. D, Henry, M. L, et al. The high prevalence of severe early posttransplant renal allograft pathology inhepatitis C positive recipients," Transplantation, (1996). , 62(8), 1054-1059.

[16] Cosio, F. G, Roche, Z, Agarwal, A, et al. Prevalence of hepatitis C in patients with idiopathic glomerulopathies in native and transplant kidneys. Am J Kidney Dis (1996).

[17] Cosio, F. G, Sedmak, D. D, Henry, M. L, et al. The high prevalence of severe early post-transplant renal allograft pathology in hepatitis $\mathrm{C}$ positive recipients. Transplantation (1996).

[18] Cruzado, J, Carrera, M, Torras, J, \& Griny, J ' o. Hepatitis C virus infection and de novo glomerular lesions in renal allografts," American Journal of Transplantation, (2001). , 1(2), 171-178.

[19] Delladetsima, I, Psichogiou, M, Sypsa, V, et al. The course of hepatitis C virus infection in pretransplantation antihepatitis $C$ virus-negative renal transplant recipients: a retrospective follow-up study," American Journal of Kidney Diseases, (2006). , 47(2), 309-316.

[20] Fabrizi, F, Poordad, F, \& Martin, P. Hepatitis C infection and the patient with endstage renal disease," Hepatology, (2002). , 36(1), 3-10. 
[21] Fabrizi, F, Martin, P, Dixit, V, Bunnapradist, S, \& Dulai, G. Meta-analysis: effect of hepatitis $C$ virus infection on mortality in dialysis," Alimentary Pharmacology and Therapeutics,(2004). , 20(11-12), 1271-1277.

[22] Fabrizi, F, Martin, P, Dixit, V, Bunnapradist, S, \& Dulai, G. Hepatitis C virus antibody status and survival after renal transplantation: meta-analysis of observational studies," American Journal of Transplantation, (2005). , 5(6), 1452-1461.

[23] Fabrizi, F, Takkouche, B, Lunghi, G, Dixit, V, Messa, P, \& Martin, P. The impact of hepatitis $C$ virus infection on survival in dialysis patients: meta-analysis of observational studies," Journal of Viral Hepatitis, (2007). , 14(10), 697-703.

[24] Finelli, L, Miller, J, Tokars, J, \& Arduino, M. National surveillance of dialysis-associated diseases in the United States, 2002," Seminars in Dialysis, (2005). , 18(1), 52-61.

[25] Fissell, R, Bragg-gresham, J, Woods, J, et al. Patterns of hepatitis C prevalence and seroconversion in hemodialysis units from three continents: the DOOPS," Kidney International, (2004). , 65(6), 2335-2342.

[26] Gheith, O. Dilemma of HCV infection in renal transplant recipients". International Journal of Nephrology 2011: 471214, (2011). doi:

[27] Goodkin, D, Bragg-gresham, J, Koenig, K, et al. Association of comorbid conditions and mortality in hemodialysis patients in Europe, Japan, and the United States: the dialysis outcomes and practice patterns study (DOPPS)," Journal of the American Society of Nephrology, (2003). , 14(12), 3270-3277.

[28] Gürsoy, M, Köksal, R, Karavelioglu, D, Colak, T, Gür, G, Ozdemir, N, Boyacioglu, S, \& Bilgin, N. Pretransplantation alpha-interferon therapy and the effect of hepatitis $C$ virus infection on kidney allograft recipients. Transplant Proc. (2000).

[29] Jadoul, M, Poignet, J, Geddes, C, et al. The changing epidemiology of hepatitis C virus infection in haemodialysis: European multicentre study," Nephrology Dialysis Transplantation, (2004). , 19(4), 904-909.

[30] Kidney disease: improving global outcome (KDIGO)KDIGO clinical practice guidelines for the prevention, diagnosis, evaluation, and treatment of hepatitis $\mathrm{C}$ in chronic kidney disease. Kidney Int Suppl (2008). suppl 109):s1

[31] KDIGO clinical practice guidelines for the preventiondiagnosis, evaluation, and treatment of hepatitis C in chronic kidney disease. Kidney Int (2008). Suppl 109):S1.

[32] Kim, E, Ko, H, \& Yoshida, E. (2011). Treatment issues surrounding hepatitis c in renal transplantation: A review. Annals of hepatology, 10(1), 5-14.

[33] Knoll, G. A, Tankersley, M. R, Lee, J. Y, et al. The impact of renal transplantation on survival in hepatitis C-positive end-stage renal disease patients. Am J Kidney Dis (1997). 
[34] Legendre, C, \& Garrigue, V. Le Bihan C, et al. Harmful long-term impact of hepatitis $C$ virus infection in kidney transplant recipients. Transplantation (1998).

[35] Mahmoud, I, Sobh, M, Habashi, A, et al. Interferon therapy in hemodialysis patients with chronic hepatitis C: study of tolerance, efficacy and post-transplantation course," Nephron Clinical Practice, (2005). , 100(4), c133-c139.

[36] Maluf, D. G, Fisher, R. A, King, A. L, et al. Hepatitis C virus infection and kidney transplantation: predictors of patient and graft survival. Transplantation (2007).

[37] Maluf, D, Archer, K, \& Mas, V. Kidney grafts from HCV-positive donors: advantages and disadvantages," Transplantation Proceedings, (2010). , 42(7), 2436-2446.

[38] Mendez, R, Shahawy, M, Obispo, E, et al. Four years follow up of hepatitis C positive kidneys into hepatitis C negative recipients- Prospective study. J Am Soc Nephrol (1995).

[39] Misiani, R, Bellavita, P, Fenili, D, Vicari, O, Marchesi, D, Sironi, P. L, Zilio, P, Vernocchi, A, \& Massazza, M. Venderamin G: Interferon alfa-2a therapy in cryoglobulinenia associated with hepatitis C virus. N Engl J Med , 330, 751-756.

[40] Morales, J, Pascual-capdevila, J, Campistol, J, et al. Membranous glomerulonephritis associated with hepatitis $C$ virus infection in renal transplant patients," Transplantation, (1997). , 63(11), 1634-1639.

[41] Morales, J. Marc'en R, Andres A, et al., "Renal transplantation in patients with hepatitis C virus antibody. A long national experience," NDT Plus, supplement 2, (2010). , 3, ii41-ii46.

[42] Natov, S. Transmission of viral hepatitis by kidney transplantation:donor evaluation and transplant policies (part 1:hepatitis B virus)," Transplant Infectious Disease, (2002). , 4(3), 124-131.

[43] Natov, S. N, Lau, J. Y, Ruthazer, R, et al. Hepatitis C virus genotype does not affect patient survival among renal transplant candidates. The New England Organ Bank Hepatitis C Study Group. Kidney Int (1999).

[44] Natov, S, \& Pereira, B. (2012). Hepatitis c virus infection and renal translpantation. In D. Brennan \& A. Sheridan (Eds.), Retrieved from http://www.uptodate.com/contents/ hepatitis-c-virus-infection-and-renal-transplantation

[45] Natov, S, \& Pereira, B. (2012). Renal disease associated with hepatitis c virus after renal transplantation. In D. Brennan, M. Hirsch \& A. Sheridan (Eds.), Retrieved from http://www.uptodate.com/contents/renal-disease-associated-with-hepatitis-c-virusafter-renal-tranplantation

[46] Northup, P, Argo, C, Nguyen, D, et al. Liver allografts from hepatitis c positive donors can offer good outcomes in hepatitis $C$ positive recipients: a us national transplant registry analysis," Transplant International, (2010). , 23(10), 1038-1044. 
[47] Ozdemir, B, Ozdemir, F, Sezer, S, Colak, T, \& Haberal, M. De novo glomerulonephritis in renal allografts with hepatitis C virus infection," Transplantation Proceedings, (2006). , 38(2), 492-495.

[48] Pawlotsky JM: Molecular diagnosis of viral hepatitis Gstroenterology 122: 1554-1568, (2002).

[49] Pedroso, S, Martins, L, Fonseca, I, et al. Impact of Hepatitis C virus on renal transplantation: Association with poor survival. Transplantation Proceedings, (2006). doi:j.transproceed.2006.06.065, 38, 1890-1894.

[50] Periera, B. J, Milford, E. L, Kirkman, R. L, \& Levey, A. S. Transmission of hepatitis C virus by organ transplantation. N Engl J Med (1991).

[51] Periera, B. J, Wright, T. L, Schmid, C. H, et al. Screening and confirmatory testing of cadaver organ donors for hepatitis C virus infection: a U.S. National Collaborative Study, Kidney Int (1994).

[52] Pereira, B, Wright, T, Schmid, C, et al. Screening and confirmatory testing of cadaver organ donors for hepatitis C virus infection: a U.S. national collaborative study," Kidney International, (1994). , 46(3), 886-892.

[53] Periera, B. J, Wright, T. L, Schmid, C. H, \& Levey, A. S. The impact of pretransplantation hepatitis $\mathrm{C}$ infection on the outcome of renal transplantation. Transplantation (1995).

[54] Periera, B. J, Wright, T. L, Schmid, C. H, \& Levey, A. S. Transmission of hepatitis C transmission by organ transplantation. The New England Organ Bank Hepatitis C Study Group. Lancet (1995).

[55] Pereira, B, \& Levey, A. Hepatitis C virus infection in dialysis and renal transplantation," Kidney International, (1997). , 51(4), 981-999.

[56] Pereira, B. J, Natov, S. N, Bouthot, B. A, et al. Effects of hepatitis C infection and renal transplantation on survival in end-stage renal disease. The New England Organ Bank Hepatitis C Study Group. Kidney Int (1998).

[57] Pirsch, J, Heisey, D, \& Allesandro, D. A, et al. Transplantation of hepatitis C (HCV) kidneys: Defining the risks (abstract). 14th Annual Meeting of the American Society of Transplant Physicians, Chicago, May 14-17, (1995). , 98.

[58] Poynard, T, Ratziu, V, Charlotte, F, Goodman, Z, Mchutchison, J, \& Albrecht, J. Rates and risk factors of liver fibrosis progression in patients with chronic hepatitis $\mathrm{C}^{\prime \prime}$ Journal of Hepatology, (2001). , 34(5), 730-739.

[59] Rostaing, L, Izopet, J, Sandres, K, et al. Changes in hepatitis C virus RNA viremia concentrations in long-term renal transplant patients after introduction of Mycophenolate mofetil. Transplantation (2000). 
[60] Roth, D, Cirocco, R, Zucker, K, et al. De novo membranoproliferative glomerulonephritis in hepatitis C virus infected renal allograft recipients," Transplantation, (1995). , 59(12), 1676-1682.

[61] Roth, D, Zucker, K, Cirocco, R, et al. A prospective study of hepatitis C virus infection in renal allograft recipients. Transplantation (1996).

[62] Shah, P, Vanikar, A, Gumber, M, Patel, H, Kute, V, Godara, S, \& Trivedi, H. (2011). Renal transplantation in hepatitis c positive patients: A single centre experience. Journal of transplantation, doi:, 2011, 1-5.

[63] Scott, D, Wong, J, Spicer, T, et al. Adverse impact of hepatitis C virus infection on renal replacement therapy and renal transplant patients in Australia and New Zealand," Transplantation, (2010). , 90(11), 1165-1171.

[64] Terrault, N, \& Adey, D. (2007). The kidney transplant recipient with hepatitis c infection pre- and posttransplantation treatment. American society of nephrology, doi:CJN.02930806, 2, 563-575.

[65] Toth, C. M, Pascual, M, Chung, R. T, et al. Hepatitis C virus-associated fibrosing cholestatic hepatitis after renal transplantation: response to interferon-alpha therapy. Transplantation (1998).

[66] Watashi, K, Hijikata, M, Hosaka, M, et al. Cyclosporin A suppresses replication of hepatitis C virus genome in cultured hepatocytes. Hepatology (2003).

[67] Zylberberg, H, Nalpas, B, Carnot, F, et al. Severe evolution of chronic hepatitis C in renal transplantation: a case control study. Nephrol Dial Transplant (2002).

[68] Zylberberg, H, Nalpas, B, Carnot, F, et al. Severe evolution of chronic hepatitis C in renal transplantation: a case control study," Nephrology Dialysis Transplantation, (2002). , 17(1), 129-133. 
